\title{
Testen Sie Ihr Fachwissen
}

\section{Test Your Knowledge}

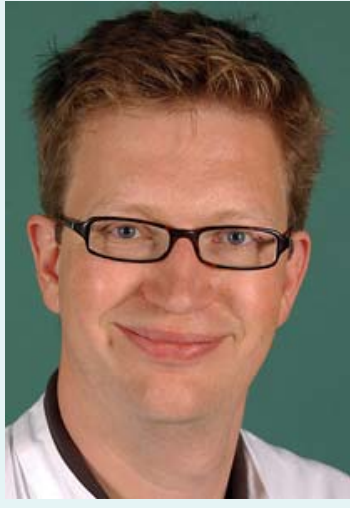

Priv.-Doz. Dr.

Christian Hallermann

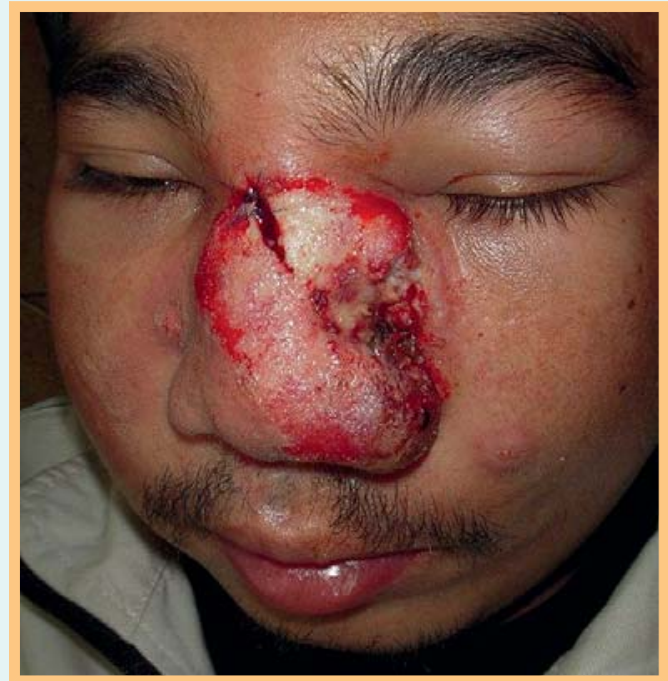

Abb. 1 27-jähriger Patient aus Kambodscha.

\section{Anamnese}

\section{$\nabla$}

27-jähriger Kambodschaner. Seit 4 Monaten zunächst moderates, dann rasches Wachstum einer schmerzlosen, hautfarbenen Plaque mit Abszedierung am linken Nasenabhang. Im Pustelabstrich massenhaft Pseudomonas aeruginosa, unter Antibiose nach Antibiogramm nur geringe Befundbesserung. Nach chirurgischer Intervention Ulzeration mit anhaltendem Ödem und zunehmenden Schmerzen. Allgemeinzustand unauffällig, kein Fieber, keine Lymphadenopathie.

\section{Klinische Differenzialdiagnosen \\ 1. Atypische Mykobakteriose \\ 2. Rhinosklerom \\ 3. Tiefe Mykose \\ 4. Kutanes Lymphom}

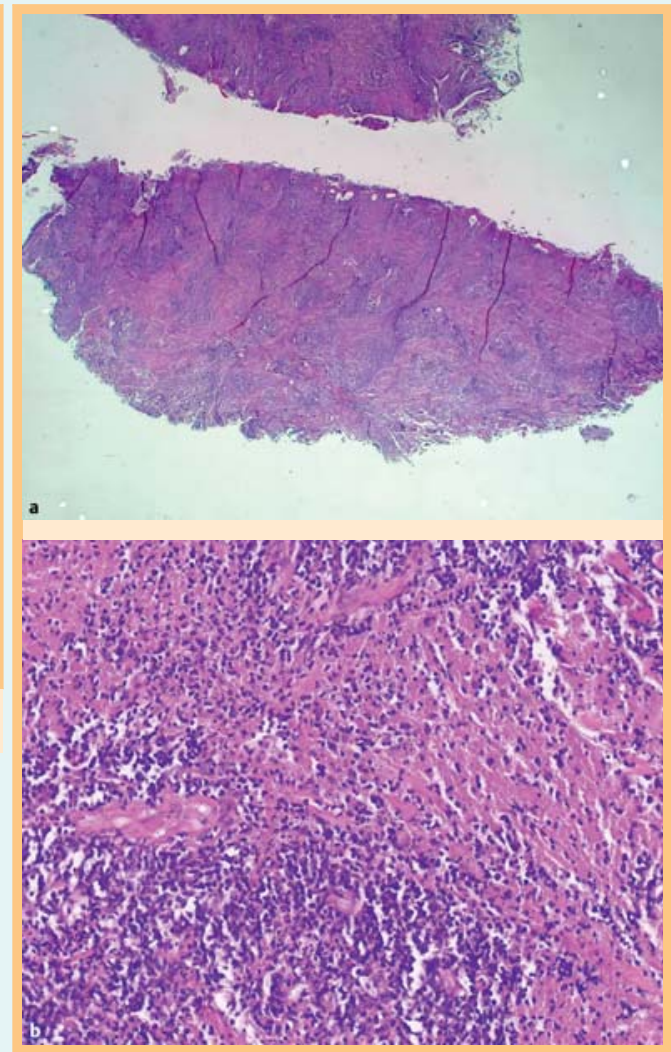

Abb. 2 a, b Wie lautet Ihre Diagnose?

\section{Befund \\ $\nabla$}

Großflächgig oberflächlich ulzerierter, plaqueförmig indurierter Tumor an der linken Nasenhälfte mit Übergang auf den Nasenrücken (Foto nach chirurgischem Débridement, $\bullet$ Abb. 1), palpatorisch gering druckschmerzhaft. Histologie siehe - Abb. 2.

(Auflösung nächste Seite)

Fachklinik Hornheide

Dorfbaumstraße 300

48157 Münster

christian.hallermann@

fachklinik-hornheide.de 


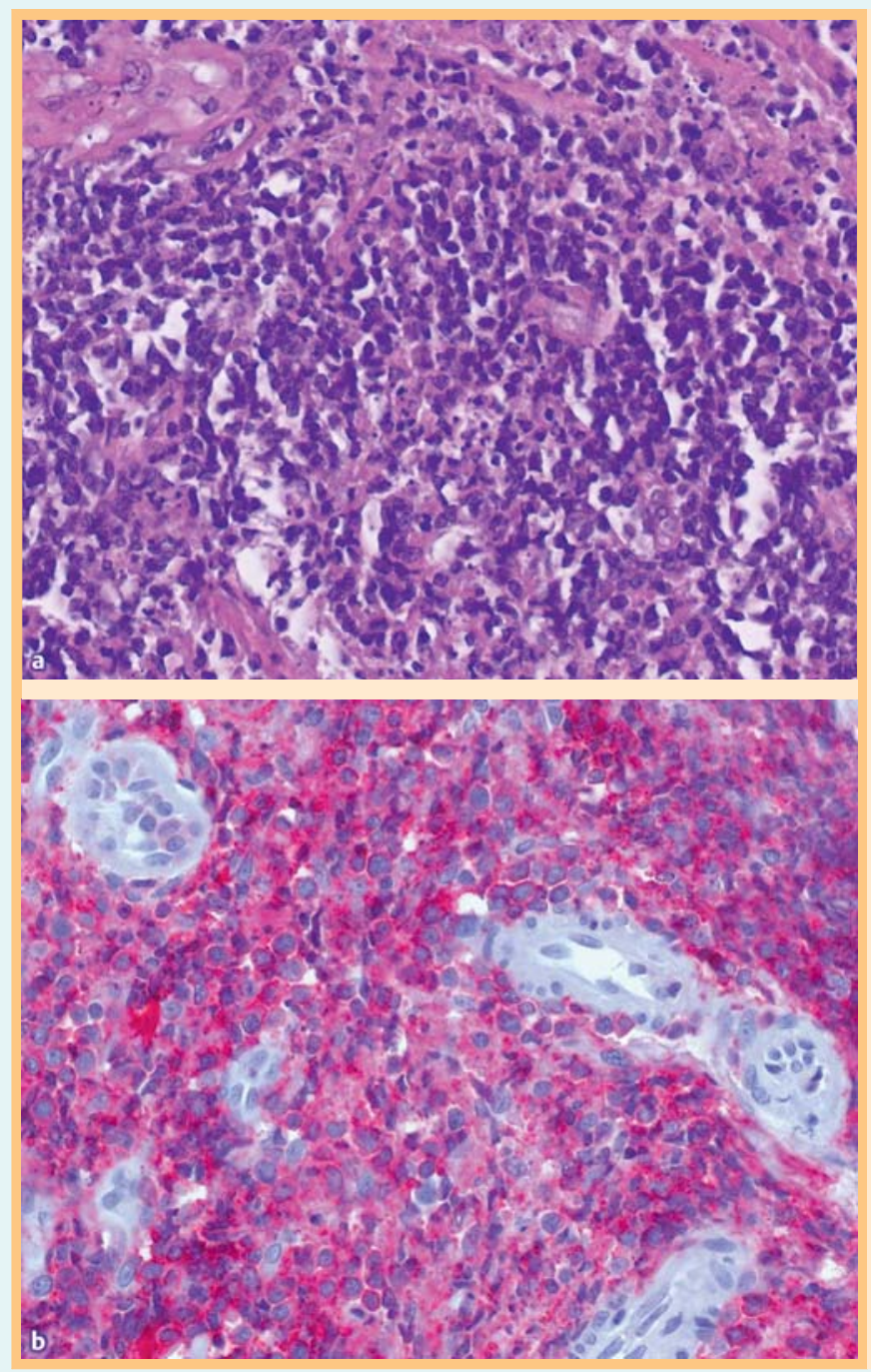

Abb. 3 a, b Nasaler Typ des extranodalen NK/T-Zell-Lymphoms.

\section{Auflösung \\ $\nabla$}

Diagnose: Extranodales NK/T-Zell-Lymphom, nasaler Typ ( Abb. $\mathbf{3}$ a: HE, $\mathbf{3}$ b: CD56).

Kommentar: Das NK/T-Zell-Lymphom vom nasalen Typ ist extrem selten und bezeichnet ein extranodales Non-Hodgkin-Lymphom, das meist an der Nasenschleimhaut oder den Nasennebenhöhlen, selten auch primär an den oberen Atemwegen auftreten kann. Die Inzidenz ist bei asiatischen Patienten deutlich höher als in Europa. Das NK/T-Zell-Lymphom ist, wie im vorliegenden Fall, häufig mit dem Nachweis von EBV-Antigen assoziiert, dessen pathogenetische Bedeutung jedoch noch nicht ausreichend charakterisiert ist. Histologisch typisch sind herdförmige
Nekrosen, die manchmal führend sein und die Diagnose erschweren können ( $\bullet$ Abb. 2a u. 2b), daneben jedoch rasenförmige Verbände aus atypischen, klein- bis mittelgroßkernigen lymphoiden Zellen ( $\bullet$ Abb.3a), die immunhistologisch CD3, CD56 ( $\bullet$ Abb. 3 b) und zytotoxische Marker exprimieren und zumeist CD4- und CD8-negativ sind. Die Prognose dieser Erkrankung ist extrem schlecht. In der Regel sterben die Patienten, unabhängig von der Therapie, welche in der Regel eine Polychemotherapie ist, wenige Monate nach Diagnosestellung. Es sind allerdings Einzelfälle mit lang anhaltender Komplettremission beschrieben worden. Der hier vorgestellte Patient starb 2 Wochen nach Diagnosestellung an einer Atemwegsobstruktion. 